\title{
Tópico, Tema y Rema: la estructura informativa en los titulares periodísticos
}

\author{
Esperanza Rocio Alcaide Lara
}

4. A pesar de que la estructura informativa ${ }^{1}$ de las oraciones ha sido uno de los aspectos de la lengua menos tratado y trabajado en los estudios linguísticos, a diferencia de los estratos sintáctico y semántico, que han recibido más atención en los mismos, es un asunto que nos ha interesado desde los comienzos de nuestras investigaciones en el campo del estudio de las oraciones de predicado no verbal. De hecho, se nos presentaba como una salida para la explicación de fenómenos como éste en el que la estructura sintáctica «usual», SN+SV, no se daba. Sin embargo, estas construcciones funcionaban, en el sentido de que cumplían sobradamente esa función primaria del lenguaje como es la de comunicar. Pero, ¿cómo es posible que una construcción que no presenta la llamada «estructura oracional SN+SV», definida como la unidad de comunicación puede cumplir dicha función?.

Ya en otro trabajo afirmamos que si bien ésta es la estructura bajo la cual se presenta más frecuentemente la invariante oración, no es la única, y que lo que define a este elemento lingüístico es la relación de predicación establecida entre algo de lo que se habla y lo que se dice sobre ese algo $^{2}$. Como podemos observar, ya en esta definición entran en juego cuestiones relativas a la estructura informativa de las oraciones.

En este trabajo tenemos un objetivo primordial: aplicar los conceptos de Tópico, Tema y Rema a aspectos prácticos de la lengua española y, más concretamente, a los llamados titulares periodísticos, los cuales presentan una estructura informativa peculiar, en tanto en cuanto no se da a otros niveles de la lengua escrita, y mucho menos en la hablada.

${ }^{1}$ Debemos advertir que cuando hablamos de estructura informativa nos estamos refiriendo a lo que de manera general se denomina el estrato informativo de la lengua, donde, como más adelante veremos se incluyen la estructura de la información y la estructura de la tematización, segín terminología de M. A. K. Halliday, al que sigue G. Rojo.

${ }^{2}$ Cfr. nuestro trabajo «Precisiones sobre el concepto de oración», en Philologia Hispalensis, Vol. V, 1991, pp. 225-238. 
Pero, antes de ello, intentaremos dejar claras algunas premisas metodológicas que creemos necesarias para entender el análisis que aquí vamos a llevar a cabo.

1. Muchos han sido los autores que han tratado el tema de la estructura informativa de la oración, manejando fundamentalmente tres aspectos básicos:

1. De un lado, nos encontramos la distinción Tema/Rema (terminología utilizada por H. Contreras, E. Bernárdez o M.L. Pardo, entre otros), Tópico/ Comentario (T.A. van Dijk), Presuposición/Foco (n. Comsky) o Tópico/ Foco (A. von Stechow), basadas en la tesis de que una cláusula ha de estar formada por «aquello de lo cual se dice algo», o «punto de partida para el discurso ulterior» ${ }^{3}$, y «lo que se dice de ello» concepto que es el que se ha venido empleando desde la Gramática de Port Royal, hasta hace relativamente poco tiempo, para definir la estructura Sujeto+Predicado, que conforma la oración.

2. Otra pareja nocional es el contraste entre Dado/Nuevo, o «información vieja»/《información nueva». Lo «dado» es la información ya conocida por el oyente, bien porque ha sido previamente proporcionada por el contexto, 0 bien porque estaba ya en el conocimiento del oyente. Lo «nuevo» es la información que el hablante añade a lo ya conocido por el oyente. En palabras de T. Jiménez Juliá, «los elementos del mensaje lingüístico podrán ser presentados como información relevante, más importante o, según el término más utilizado, 'nueva', frente a otros que serán tratados como información conocida o 'dada' por alguna circunstancia (situación, mención o contexto previo, etc.) (...). El hablante puede -y de hecho así lo hace- considerar en cada momento que ciertos elementos de un mensaje son informativamente más importantes que los demás por muy diversas razones que incluso pueden ser desconocidas por sus interlocutores» ${ }^{4}$.

3. El hablante, mediante la entonación, la posición, etc., pueden destacar uno o varios elementos y darles especial relieve. Al elemento destacado suele llamársele «foco».

En torno a estos términos ha habido mucha controversia debido a que no todos los autores están de acuerdo en la forma de tratarlos y distinguirlos ${ }^{5}$. De hecho, esta serie de nociones han sido frecuentemente entremezcladas por lo que no se ha llegado a conclusiones rigurosas acerca de estos conceptos.

${ }^{3}$ T. Jiménez Juliá, Aproximación al estudio de las funciones informativas, Málaga, Ágora, 1986, p. 57.

${ }^{4}$ Ídem, p. 8.

${ }^{5} \mathrm{Al}$ decir de G. Rojo, «aunque haya coincidencias y sean perfectamente explicables, queda claro que estamos ante nociones pertenecientes a ámbitos distintos. No haberlas diferenciado suficientemente y haberlas entremezclado con demasiada frecuencia explica buena parte de las dificultades con que han tropezadolos autores que se han ocupadodel estrato informativo de las secuencias». (G. Rojo, Aspectosbásicos de Sintaxis Funcional, Málaga, Ágora, 1983, p. 92). 
Uno de los autores que ha incurrido en este error es $\mathrm{H}$. Contreras, quien identifica Tema con lo «Dado» y Rema con lo «Nuevo». Pero hay que tener en cuenta que dentro del estrato informativo, éstos son aspectos que pertenecen a distintos ámbitos. Es evidente que en muchas ocasiones Tema y «Dado» coinciden. Sin embargo, hay veces en que Tema y «Dado» coinciden. Sin embargo, hay veces en que Tema y «Dado» no están asociados. Así lo expone M.A.K. Halliday: «la asociación del Tema con lo «dado» y el Rema con lo «nuevo» está sujeta al habitual principio de «buenas razones» (...)-hay libertad de elección pero el Tema se asociará con lo «dado» y el Rema con lo «nuevo», a menos que haya buenas razones para escoger otra organización» ${ }^{6}$. Junto a esto más adelante afirma: «dado y nuevo difieren de Tema y Rema, a pesar de ser ambos funciones textuales, en que «dado» significa 'aquí hay un punto de contacto con lo que usted (tú) y sabe(s)' (y, por consiguiente, no va enlazado a ningún elemento de la estructura de la cláusula), mientras que «Tema» significa 'aquí está el encabezamiento de lo que estoy diciendo'» ${ }^{7}$. El Tema en este autor equivaldría a lo que habitualmente se llama sujeto psicológico ${ }^{8}$. Interpreta el Tema como «aquello de lo que se habla (o de lo que quiere hablar) el emisor de la secuencia siendo, de esta manera, independiente de si su punto de partida en la organización de la cláusula es un elemento ya conocido o desconocido aún. Si aquello de lo que se halla es algo conocido, Tema y «dado» coinciden; pero si no es así, es decir, si el Tema es un elemento desconocido, éste coincidirá con la llamada «información nueva». Así pues, Tema y «dado» no tienen por qué ser equivalente, ya que pertenecen a ámbitos distintos. No en vano T. Jiménez Juliá nos dice: «si la estructura de la información de acuerdo con los sentimientos que le sugiere su propio discurso, sin que para ello interviniera para nada el tipo de estructura sintáctica en el que se enmarcaba tal información, el Tema representa el modo en que el hablante distribuye con elementos de la cláusula para construir el mensaje de acuerdo con sus prioridades informativas» ${ }^{9}$. De hecho, G. Rojo, siguiendo a Halliday, incluye la dicotomía Tema/Rema en la estructura de la tematización y lo dado/nuevo en la estructura de la información ${ }^{10}$.

$\mathrm{Si}$, como vemos, en torno a estos términos ha habido, y sigue habiendo, mucha controversia, debido a que no todos los autores están de acuerdo en la forma de tratarlos y distinguirlos, en lo que sí coinciden todos los estudiosos de estas cuestiones es en lo siguiente:

1. Mientras que el elemento «dado» es optativo, es decir, puede estar explícito en el discurso, o quedar implícito en el contexto extralingüístico, el

\footnotetext{
${ }^{6}$ M. A. K. Halliday, «Estructura y función del lenguaje», en J. Lyons, Nuevos horizontes de la Lingüistica, Madrid, Alianza, 1975, p. 170.

${ }^{7}$ Ídem, p. 171.

${ }^{8}$ Atendemos aquí a la distinción entre sujeto gramatical (el que concuerda en número y persona con el verbo), sujeto lógico (el que efectúa la acción expresada por el verbo) y sujeto psicológico (aquello de lo que se habla).

${ }^{9}$ T. Jiménez Juliá, Op. Cit., p. 56.

${ }^{10}$ Cfr. G. Rojo, Op. Cit., pp. 89-95.
} 
elemento «nuevo» es obligatorio. De lo contrario no habrá información. 2. El elemento «dado» suele preceder al elemento «nuevo», el cual estará marcado por llevar el acento principal.

Por otra parte, debíamos preguntarnos qué tipo de contenido es el aportado por los recursos informativos. Desde nuestro punto de vista, el contenido que aporta al mensaje las funciones informativas es cualitativamente distinto al contenido semántico, identificado con el meramente representativo. En nuestra opinión, los valores 'información dada' e 'información nueva' tienen un carácter pragmático, ya que dependen totalmente del conocimiento de los interlocutores, así como del contexto o situación previa, por la que son determinados. Así pues, son elementos pragmáticos que condicionan el significado informativo del mensaje, pues lo «dado» o lo «nuevo» está en la mente de los interlocutores, y no en ningún presupuesto de tipo sintáctico o semántico. De ahí que digamos que este significado sea de tipo pragmático, y no óntico o referencial, es decir, fuera del contexto que le dará su sentido completo. En esta misma línea habla G. Rojo de la dicotomía Tema/Rema, pues al situarla dentro del estrato informativo de la lengua responde a las intenciones comunicativas de los hablantes.

2. Veamos cómo lo expuesto arriba se refleja en casos concretos. Observemos para ello los siguientes ejemplos ${ }^{11}$ :

/1/. Maria- Porque iya ha llegado!

Yerma. iA los cinco meses!

(F. García Lorca, Yerma, Madrid, Espasa-Calpe, 1979, p. 133)

12/. Entonces la universidad, desde luego, ha variado mucho para bien y para mal. Sí exactamente. En el sentido de más posibilidades y de menos tonterías, y de un poco más de comprensión, sí.

(V. Lamíquiz, M. A. Pineda, Encuestas del habla urbana de Sevilla. Nivel Culto, Sevilla, P.U.S., 1983, p. 228).

Los casos /1/ y /2/ presentan la siguiente estructura informativa:

TEMA Ø

$\operatorname{REMA} \varnothing+(\ldots)$

DADO $\varnothing$

NUEVO $(\ldots)^{12}$

${ }^{11}$ Advertimos que los ejemplos que presentamos son casos de oraciones de predicado no verbal, tipo de oración que hemos estudiado ya en otros trabajos, y que responden a nuestro objetivo de demostrar cómo dado/ nuevo y Tema/Rema no son dicotomías equivalentes.

${ }^{12}$ En este tipo de gráficos, el símbolo «(...)» representa bien la secuencia completa, bien parte de ésta, pero siempre hace referencia a elementos que están explícitos en la misma. En contraposición, «0» se refiere a elementos que están ausentes, y, por ello, han de ser presupuestos, ya sea por medio del contexto linguístico, ya por medio del contexto extralingüístico. Así pues, en el ejemplo 1:

$\mathrm{DADO}=($ el niño ya ha llegado $) 0$

NUEVO $=a$ los cinco meses $(. .$.

$\mathrm{TEMA}=(E l$ niño $) 0$

REMA $=A$ los cinco meses $(. .$. 
Podemos apreciar, pues, que este tipo de construcciones se caracteriza por ser «pura información», en el sentido de que no presentan ningún tipo de elemento conocido, y, por lo tanto, redundante en caso de que apareciese. De esta forma, responden perfectamente a la función comunicativa, ya que son secuencias plenas de información.

Desde el punto de vista Tema/Rema, vemos que el Tema siempre queda implícito, estando presente en el contexto extralinguístico, como en $/ 1 /$ (donde hay que recurrir a los conocimientos implícitos de los interlocutores) o en el contex to lingüístico, como en 13/.

Por consiguiente, son construcciones que podríamos calificar como «puramente remáticas» en cuanto que lo que aparece explícitamente es el rema.

Por otro lado, en los dos casos, al estar ausente tanto el Tema, soporte del mensaje, como la información «dada» o «vieja», los hablantes tendrán que recurrir a la presuposición, ya sea intratextual como en $/ 2 /$, ya sea extratextual, como en $/ 1$ / para llegar a la comprensión del significado exacto de la secuencia expresada. Así pues, si el hablante no presupone una serie de elementos no comprenderá en su totalidad el sentido de la expresión. Estos elementos son:

En /1/ el niño (Tema e información dada) y llegar(parte del Rema e información dada).

i(El niño ha llegado) a los cinco meses!

En /2/ Universidad(Tema e información dada) y variar (parte del Rema e información dada).

En el sentido de más posibilidades y de menos tonterías, y de un poco más de comprensión, (la Universidad) si (ha variado).

El siguiente ejemplo refleja de diferente forma a la que hemos estudiado anteriormente la no univocidad entre Tema e información dada:

13/. Madre. La navaja, la navaja... Malditas sean todas y el bribón que las inventó.

Novio. Vamos a otro asunto.

Madre. Y las escopetas, y las pistolas, y el cuchillo más pequeño, y hasta las azadas y los bieldos de la era.

(F. García Lorca, Bodas de sangre, Madrid, Espasa-Calpe, 1979, p. 12).

En este caso podemos apreciar que lo que compone toda la secuencia subrayada es información nueva, la cual por lo tanto, no aparece ni en el contexto lingüístico ni en el extralingüístico.

Pero, a la vez, todos estos elementos no forman parte del rema, sino que constituyen el Tema de la construcción, puesto que son «los objetos de los que se habla», o acerca de los que se predica. Por consiguiente, es una estructura plenamente «temática» que cumple su función informativa, ya que se compone exclusivamente de informaciónnueva, que es lo efectivamente obligatorio desde el punto de vista comunicativo. 
Asimismo, lo que es el cuerpo del mensaje, o sea, el Rema o predicación, ha de ser presupuesto intratextualmente por el oyente, estando explícito en el contexto lingüístico anterior, como información vieja o dada.

De esta forma, en el ejemplo/3/, el Tema coincide con la información nueva, y el Rema con la información dada.

Vemos, pues, que afirmaciones tan tajantes como la de H. Contreras, quien identifica Tema/Rema con Dado/Nuevo, son incoherentes cuando nos enfrentamos a casos como éste que hemos analizado, en que la correspondencia es

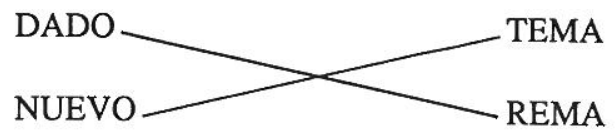

Pero no son éstas las únicas estructuras que pueden aparecer, pues tenemos construcciones que presentan una estructura tal:

$\operatorname{TEMA}(\ldots) \quad \operatorname{REMA} \varnothing+(\ldots)$

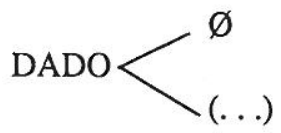

NUEVO (. .)

En este tipo de secuencias, tanto el Tema como el Rema, a excepción del elemento verbal, están presentes sin tener que ser presupuestos.

En lo referente a la dicotomía Dado/Nuevo, lo nuevo está lógicamente presente, ya que sin ello no habría información y la oración sería comunicativamente nula.

Lo viejo o dado tiene dos posibilidades:

1. Puede estar eludido y, por consiguiente, ha de ser presupuesto.

2. Puede estar en parte explícito.

Veamos algunos ejemplos:

14/. Bueno en cuanto a mis padres, el nombre de mi padre es Francisco, el de mimadre, Dolores, y ninguno de ellos son naturales de Sevilla.

(V. Lamíquiz-M. A. Pineda, Op. Cit., p. 15).

15/. Mi padre es natural de un pueblo, de un pueblecito de la provincia de Málaga, que se llama Sierra Yegua, bueno Sierra de Yegua, Sierra Yegua es como le dicen allí. Y mi madre de un pueblo cercano de alli, de la provincia de Sevilla, que es Casariches.

(V. Lamíquiz-M. A. Pineda, Op. Cit., p. 15). 
En los casos /4/ y /5/el Tema está explícito: el (nombre) de mi madre y mi madre, respectivamente, mientras que el Rema sería todo lo demás.

En cuanto a la dicotomía Dado/Nuevo, tenemos que decir que, en estos ejemplos, lo «dado» está explícito sólo en parte, quedando información dada implícita en el contexto: el elemento verbal. Por lo tanto, el oyente ha de presuponerlo.

Otra cuestión que observamos en casos como éstos es que presentan una estructura contrastiva, estructura que vemos también en ejemplos como el siguiente:

/6/. Agustín García Calvo no me daba. Me dio latín y Griego en primero y parte en segundo.

- Y ¿dentro de la especialidad?

- Pregunta un tanto difícil, porque, no sé, quizá, quizás, algunas veces López Estrada, otras veces Feliciano, no sé. (V. Lamíquiz-M. A. Pineda, Op. Cit., 0. 45).

Como afirma L. Fant, el contraste «es uno de los factores que llamamos estructura informativa» ${ }^{13}$ y contribuye a dar más fuerza a lo que es la información nueva.

Estas secuencias que nos ocupan están compuestas por los llamados «focos de contraste», explícitos en estos casos, mientras que la base del contraste está implícita teniendo que ser presupuesta por medio del contex to lingüístico.

Observemos esto:

$\begin{array}{ccc}\text { /4/. El nombre de mi padre } & \text { es } & \text { Francisco, } \\ \text { F.C.1 } & \text { B.C. } & \text { F.C.2 } \\ \text { el de mi madre } & \text { Dolores } & \\ \text { F.C.1' } & \text { F.C.2 } & \end{array}$

15/. Mi padre es F.C.1 B.C. natural de un pueblo, de un pueblecito de la provincia de Málaga... Y Y mi madre, F.C.1' de un pueblo cercano de alli, de la provincia de Sevilla. F.C.2،

$\begin{array}{cc}\text { /6./ Algunas veces, } & \text { López Estrada } \\ \text { F.C.1 } & \text { F.C.2 } \\ \text { otras veces, } & \text { Feliciano } \\ \text { F.C.1‘ } & \text { F.C.2‘ }\end{array}$

Estos casos constituyen lo que Fant llama «enunciados contrastivos biseriales» ${ }^{14}$, ya que están compuestos de dos series de focos contrastivos. Éstas son:

\footnotetext{
${ }^{13}$ L. Fant, Estructurainformativa en español. Estudio sintáctico y entonativo, Uppsala, Almquist \& Wiksell, 1984, p. 75.

${ }^{14}$ Ídem, p. 76.
} 
el nombre de mi padre
el (nombre) de mi madre en $/ 4 /$

$\mid \begin{aligned} & \text { Mi padre } \\ & \text { Mi madre }\end{aligned}$
en $/ 5 /$, y $\left|\begin{array}{l}\text { Algunas veces } \\ \text { Otras veces }\end{array}\right|$.
en $/ 6 /$.
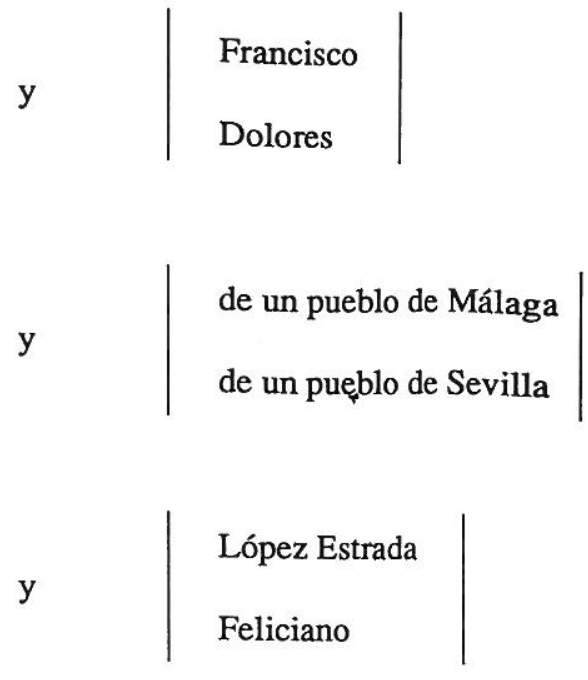

Según este autor «lo constitutivo de una pareja de focos es que ambos sean miembros de un mismo conjunto paradigmático y que se excluyan mutuamente de alguna forma» ${ }^{15}$.

Esto es evidente si examinamos los casos dados. Por ejemplo, mi padre/mi madre pertenecen al mismo paradigma, y, por tanto, se excluyen, al igual que ocurre con algunas veces/otras veces.

En su funcionamiento, el segundo foco de una pareja o serie contrastiva mantiene, según Fant, una relación correferencial conel primero, considerando aéste un antecedente de aquel ${ }^{16}$.

Pero lo que nos interesa destacar de los enunciados contrastivos biseriales es que en éstos el foco que va en segundo lugar parece ser en la mayoría de las ocasiones la «información nueva», como ocurre en /4/ y /5/, o la «información más importante», como en $/ 6 /$. Por lo tanto, podemos afirmar que el contraste es una forma de resaltar la información nueva y la más importante a los ojos del hablante.

Creemos que todos los ejemplos que hemos ido mostrando hasta el momento dan crédito a lo que dijimos en la primera parte de este estudio: Las dicotomías Tema/Rema y Dado/Nuevo pertenecen a ámbitos distintos de la oración, y, a pesar de que general-

${ }^{15}$ Ibídem, p. 76.

${ }^{16}$ Debemos recordar que para L. Fant, la relación de correferencia no ha de ser necesariamente una relación de identidad individual, sino que puede existir una relación de identidad en el plano genérico. Esto es: «dos términos o secuencias implican la misma identificación genérica», aun cuando presenten «diferentes identificaciones individuales». Incluso, «muy frecuentemente no hay identidad entre antecedente y anáfora en ninguno de los dos planos (...). La razón de que siga existiendo una relación anafórica en estos enlaces, es que los términos acoplados mantengan entre sí una afinidad semántica: se trata de la relación mantenida entre hipónimo e hiperónimo, o entre dos hipónimos paralelos» (L. Fant, Op. cit., p. 70). 
mente ambas se estudian en el estrato informativo, Tema/Rema entra en lo que se denomina la estructura de la tematización, mientras que Dado/Nuevo conforman la llamada estructura de la información según terminología de Halliday, siendo ambas oposiciones no equivalentes. Así lo demuestra la representación gráfica de estos elementos en los ejemplos que hemos ido estudiando:

\begin{tabular}{|c|c|c|c|c|c|c|}
\hline $\begin{array}{l}0 \\
? \\
? \\
? \\
Z\end{array}$ & 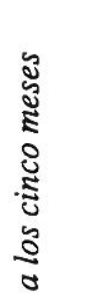 & 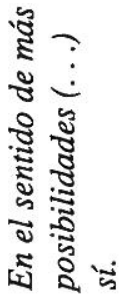 & 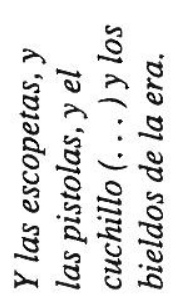 & $\frac{\check{0}}{\frac{0}{0}}$ & 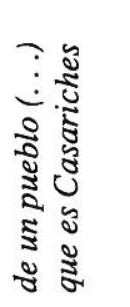 & 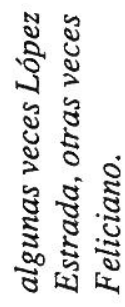 \\
\hline 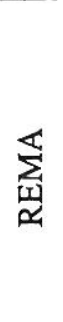 & 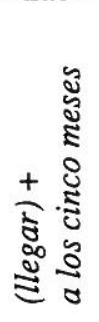 & 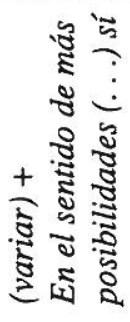 & 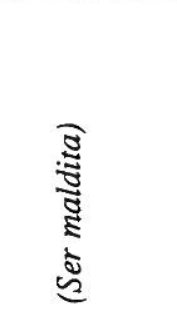 & 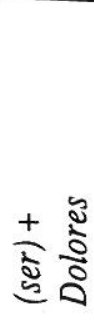 & 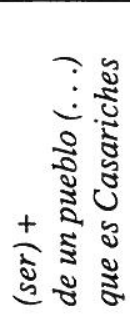 & 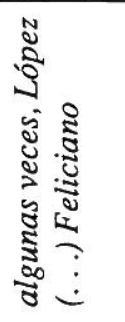 \\
\hline $\begin{array}{l}8 \\
8 \\
\varrho\end{array}$ & 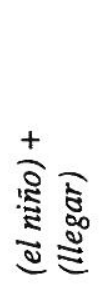 & 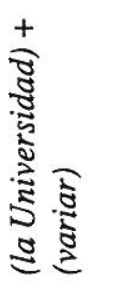 & 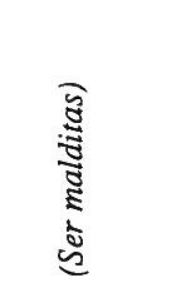 & 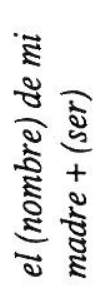 & 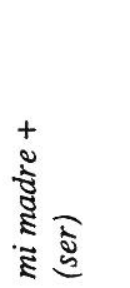 & 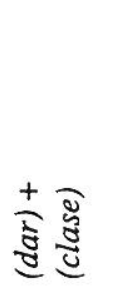 \\
\hline 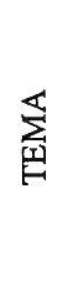 & 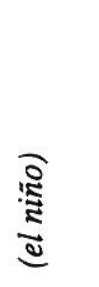 & 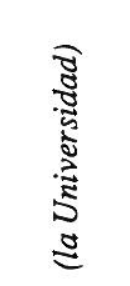 & 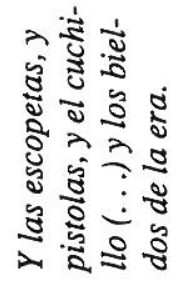 & 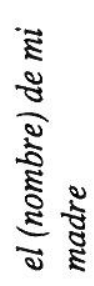 & 竎 & 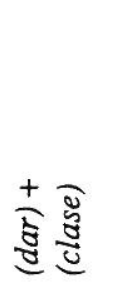 \\
\hline & $\nexists$ & ते & $\bar{n}$ & Ð & 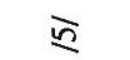 & 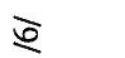 \\
\hline
\end{tabular}


Como vemos, sólo es el caso /6/ se da la correspondencia

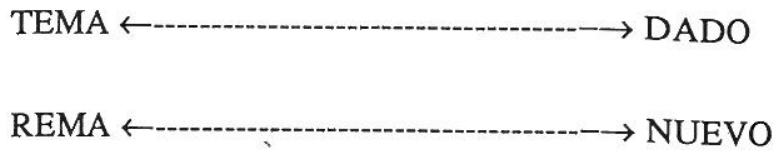

En los demás casos, esto no se da, pues en $/ 1 /, / 2 /, / 4 /$ y $/ 5 /$ tenemos:

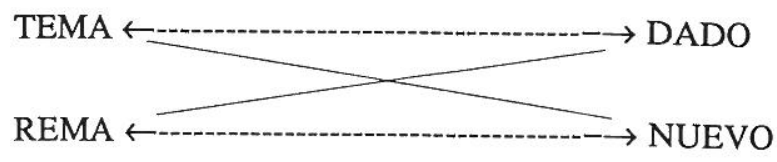

$y$ en $/ 3 /$ :

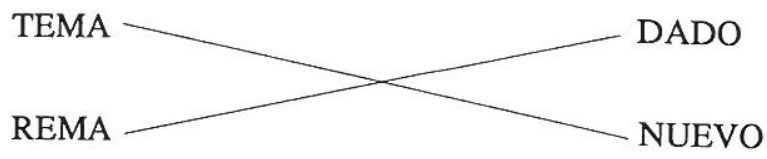

Hemos estudiado toda esta serie de aspectos en secuencias pertenecientes a registros como el oral o el literario (éste último de marcado carácter coloquial), aunque con ello no queremös decir que hayan sido registradas todas las posibilidades en cuanto a los tipos de estructura informativa, que se dan en la lengua, pues en un trabajo de estas dimensiones sería una tarea casi imposible. Pasemos ahora a estudiar estos elementos en un registro que se caracteriza por una serie de peculiaridades, entre las que se encuentra determinado tipo de estructura temática que lo hace distinto a cualquier registro lingüístico: los titulares periodísticos.

3. De manera general, podemos decir que básicamente, los titulares periodísticos presentan características similares a las que se dan en otras construcciones ya estudiadas anteriormente, que nos pertenecen a este tipo de lenguaje. Observemos varios ejemplos:

71. Un militar licenciado en Derecho, nuevo jefe de la Policía Local de Cádiz. (ABC, 11-9-88)

18/. La corrida Iberoamericana de Huelva, suspendida por segunda vez consecutiva. Malestar en la afición onubense por esta decisión. (ABC 23-10-88).

19/. El Grupo de los Siete buscará las medidas para paliar el efecto de la guerra. (ABC, 21-1-91).

/10/. Estados Unidos abre desde Turquía un segundo frente de la campaña aérea . (ABC, 21-1-91). 
Los casos $/ /$ y /8/ son construcciones bimembres, cuyo verbo, eludido, se presupone con ayuda tanto del contexto lingüístico. como del situacional.

Su estructura temática e informativa es la siguiente:

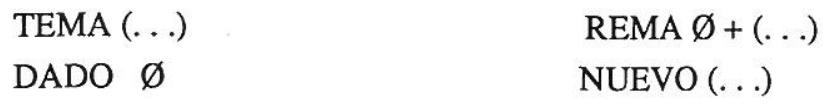

estructura que ya hemos visto en ejemplos anteriores.

En los ejemplos 9 y 10, al estar presente también el elemento verbal, el rema, del cual forma parte éste, está completamente explícito. Su estructura es pues:
TEMA (...)
REMA (...)
DADO $\varnothing$
NUEVO (. .)

También hay que advertir que si algo caracteriza al lenguaje periodístico es el afán por ofrecer información nueva. De ahí que lo «dado» o «información vieja» sea $\emptyset$. Pero podríamos decirque, por jemplo, en/8/,/9/y/10/, la corridalberoamericanade Huelva, el Grupo de los Siete, Estados Unidos y Turquía, sean elementos conocidos porel emisor y el receptor. Pero al estar situados en el encabezamiento de la noticia, en el titular, son elementos tratados como información nueva para el receptor, pues no ha aparecido antes en el mensaje completo que sería la noticia.

Observemos ahora otros ejemplos como son los siguientes:

/11/. Barcelona: Once muertos al volcar un autobús de jubilados que regresaban de vacaciones. Un descuido del conductor, causa más probable del siniestro.

(ABC, 23-10-88).

/12/. Italia: Incierto futuro del Estadio Olímpico de Roma.

(ABC, 23-10-88)

/13/. País Vasco: El P.N.V., gran perdedor en beneficio de H.B. (ABC, 11-6-87).

/14/. Elecciones municipales: Los pueblos andaluces más conflictivos. (ABC, 7-6-87).

Con respecto a construcciones como /11/, /12/ y /13/, donde los elementos escindidos de la oración son topónimos, y por ello indican lugar, E. Alarcos nos dice que se trata de casos de economía lingüística, ya que se evita la utilización de la preposición en. Pero esta explicación es insuficiente, pues, como él mismo reconoce, «en estos titulares la economía lingüística es más bien escasa, puesto que en definitiva sólo se ahorra el empleo de una pieza tan modesta como es la preposición en; pero (...) la expresión adquiere especial relieve mediante la escisión que marcan gráficamente los dos 
puntos entre el encuadre locativo y la oración propiamente dicha» ${ }^{17}$. La cuestión no se reduce, pues, a un simple caso de economía lingüística.

Autores como F. Rodríguez-Izquierdo y W.L. Chafe ${ }^{18}$ señalan que en lenguas como el japonés y el chino, respectivamente, se produce este tipo de estructuras, aunque en estas lenguas la cuestión es más sencilla, puesto que el elemento tópico, que es ante lo que estamos en realidad en lo que concieme al elemento escindido de la oración, tiene un molde sintáctico perfectamente definido. Veámoslo:

\section{/15/. Zoo wa hana ga nagai.}

(Del elefante la trompa es larga).

\section{/16/. Nèi-xie shùm shu-shên da.}

(De esos árboles el tronco es grande).

El problema de la explicación de construcciones como éstas en lenguas como las indoeuropeas viene dado de una parte por la falta de marcas sintácticas que nos señalen dicho elemento (dominancia de tópico), y, de otra parte por la ambigüedad de la definición del concepto de tópico como «aquello de lo cual se habla», concepto que coincide con el de Tema, ya citado ampliamente en apartados anteriores. De esta forma, si ambos términos coinciden, en este tipo de estructuras tendríamos o dos Tópicos o dos Temas, dado que efectivamente ambos suponen «aquello de lo que se habla». Observémoslo:

Retomemos el ejemplo 13. Tenemos dos Temas o Tópicos de los que se habla: el País Vasco, por un lado; el P.N.V., por otro. Pero ¿cómo podemos tener en una oración dos Temas sobre los que se predica? W. L. Chafe se da cuenta del problema y, aunque opta por prescindir del concepto de Tópico en lenguas como las indoeuropeas, donde no existe «dominancia de Tópico», afirma: «What the topics appear to do is limit the applicability of the main predication to a certain restricted domain (...) Typically, it would seem, the topic sets a spatial, temporal, or individual framework within which the main predication holds» ${ }^{19}$.

Esta misma línea siguen Ch. Li y S.A. Thompson que, resumidamente, definen el Tópico como aquella estructura nominal que:

1. Es definida.

2. No está vinculado sintácticamente al verbo, ni seleccionado por éste en la estructura profunda.

3. Carece de función oracional, limitándose a señalar el campo situacional o temporal en que la oración va a predicar algo.

${ }^{17}$ E. Alarcos Llorach, «El lenguaje de los titulares», en F. Lázaro Carreter (ed.), Lenguaje en periodismo escrito, Madrid, Fundación Juan March, Serie Universitaria, 37, 1977, pp. 127-147, p. 142.

${ }^{18}$ Vid. F. Rodríguez-Izquierdo, «Procedimientos de topicalización en el habla culta de Sevilla», en V. Lamíquiz-F. Rodríguez+Izquierdo (eds.), Sociolingüística andaluza 3, Sevilla, P. U. S., 1985, pp. 31-49; y W. L. Chafe, «Givennes, Contrastivenes, Definitenes, Subjects, Topics and Point of view», en Ch. Li (ed.), Subject and Topic, New York, Academic Press, 1976, pp. 27-55.

${ }^{19}$ W. L. Chafe, Op. cit., p. 50. 
4. Se sitúa siempre en posición inicial ${ }^{20}$.

Siguiendo esta línea, la explicación de este tipo de estructuras que aparece de forma general en el lenguaje de los titulares periodísticos es bastante fácil:

Estamos ante un tipo de estructura temática e informativa como la siguiente:

TÓPICO (. . .)

$$
\text { TEMA (..) REMA }(\ldots)+\emptyset
$$

\section{DADO $\varnothing \quad$ NUEVO $(\ldots)$}

donde el Tema será aquello de lo que se habla o se predica, el Rema lo que se predica del Tema, y el Tópico será la manifestación del dominio o campo de aplicabilidad de la oración.

Apliquemos esto a nuestros ejemplos:

\begin{tabular}{|c|c|c|c|}
\hline & TÓPICO & TEMA & REMA \\
\cline { 2 - 4 } & Barcelona & Once muertos & $\begin{array}{l}\text { (haber) }+ \text { al vocar un } \\
\text { autobús de jubilados }\end{array}$ \\
\hline$/ 12 /$ & Italia & $\begin{array}{l}\text { Estadio Olim- } \\
\text { pico de Roma }\end{array}$ & $\begin{array}{l}\text { (tener })+ \text { incierto } \\
\text { futuro }\end{array}$ \\
\hline$/ 13 /$ & país Vasco & El P.N.V. & $\begin{array}{l}\text { (ser })+ \text { gran perdedor } \\
\text { en beneficio de H.B. }\end{array}$ \\
\hline$/ 14 /$ & $\begin{array}{l}\text { Elecciones } \\
\text { municipales }\end{array}$ & $\begin{array}{l}\text { Los pueblos } \\
\text { andaluces más } \\
\text { conflictivos }\end{array}$ & $\varnothing$ \\
\hline
\end{tabular}

${ }^{20}$ Ch. Li y S.A. Thompson, «Subject and Topic: a new Typology of language», en Ch. Li (ed.), Subject and Topic, New York, Academic Press, 1976, pp. 457-490, vid. pp. 461-466. 
Así pues, ese elemento desgajado de la oración no es más que el Tópico que señala elámbito al que es aplicable (donde se enclava) lo manifestado por la oración ${ }^{21}$. Este tipo de estructura es difícil de encontrar en el lenguaje coloquial, ya que si se producen, requieren un alto grado de atención por parte del oyente, el cual tendría que presuponer bastantes elementos (entre ellos, las marcas de dominancia de tópico). De todas formas, no debemos dudar de que efectivamente el habla de todos los días presenta casos de éstos, aunque no tan bien representados como en el lenguaje escrito, lo cual puede hacer que a los ojos del estudioso pase desapercibido. Por ejemplo:

/15/ En cuanto a ese asunto, yo no tengo más que decir.

/16/ - ¿Cuál es el Cristo que más le gusta?

- El Cristo que más me gusta. Como es natural cada sevillano tiene su Cristo... (V. Lamíquiz-M. A. Pineda, Op. Cit., p. 215).

/17/ - Y, los nombres de los prelados.

- De los prelados. Empecé por tratar mucho, diariamente, a don Marcelo Spinola y Maestre, arzobispo santo de Sevilla. (Ídem, p. 228).

El caso 15 pertenece a lo que F. Rodríguez-Izquierdo ha llamado «Tópico ortodoxo» o «presentado», «que va introducido por alguna expresión 'topicalizadora', como 'a propósito de', 'en cuanto a', 'con respectoa', 'tocante a'...» ${ }^{22}$. Este tipo de Tópico es el más utilizado en la lengua escrita no periodística y en la hablada que tiene cierto grado de elaboración.

Pero observemos los casos 16 y 17. En estos ejemplos aparece un sintagma perteneciente a la oración manifestada anteriormente por el interlocutor, que se convierte en tópico de la predicación. Estos casos entran en el grupo que F. RodríguezIzquierdo ha dado en llamar «tópicos no presentados», es decir, el Tópico «que destaca por sí mismo, por su posición sintagmática en el enunciado» ${ }^{23}$. A nuestro juicio, el mecanismo seguido en este tipo de secuencias que nos ocupa es el siguiente: El hablante repite la parte que le interesa de la pregunta o afirmación de su interlocutor para centrar su atención en ese elemento, el cual, por otra parte, podía haber sido omitido sin ningún tipo de problema para la comunicación.

Se trata, pues, en estos casos, de Tópicos condicionados por el interlocutor, es decir, surgidos por la pregunta o manifestación del mismo.

Por otro lado, la aparición de este tipo de elementos en la lengua hablada parece obedecer no tanto a un deseo de delimitar el campo de la conversación, como a una

${ }^{21}$ Autores como S. C. Dik distinguen entre Tópico y Tema, aunque invierten la terminología, es decir, para él el Tema será el elemento que especifica el universo de discurso acerca del cual se habla, el Tópico será el elemento acerca del cual se dice algo concreto (Functional Grammar, Amsterdam, North-Holland, 1978, p. 127 y ss.).

${ }^{22}$ F. Rodríguez-Izquierdo, Op. cit., p. 38.

${ }^{23}$ Ídem, p. 39. 
necesidad del hablante de repetir este elemento para mantener dicha conversación sin interrupciones ante un momento de incertidumbre o inseguridad. Podemos decir, entonces, que a diferencia de la función informativa que esta estructura pueda presentar en los titulares periodísticos, la función primordial del este tipo de elemento en la lengua coloquial o hablada es muy distinta, pues se trata, en nuestra opinión, de un elemento con claro valor fático.

Así pues, podemos decir que dos estructuras similares a simple vista, tienen muy distinta función según el registro lingüístico en que la encontremos, y, lo que es más importante, según las necesidades comunicativas del emisor.

4. De todo lo expuesto hasta el momento podemos sacar dos conclusiones fundamentales:

1. De manera general, a pesar de que en los estudios lingüísticos no ha sido tenida en cuenta, en este trabajo hemos podido comprobar cómo la estructura informativa, o si se prefiere, el estrato informativo es independiente del semántico y el sintáctico, y conforma con éstos los tres niveles en los que se organiza una secuencia.

El estudio de la misma, por tanto no estará completo si al sintáctico y el semántico, no se le une el estudio del nivel informativo, que, como afirma G. Rojo acerca de dichas funciones, «su existencia es lo único que puede explicar esos matices diferentes de significado que aparecen aunque se mantenga los esquemas semántico y sintáctico» ${ }^{24}$. Por otra parte, este estudio no será posible síno se establecen las pertinentes delimitaciones entre lo que dentro de este nivel es la estructura de la tematización y la de la información, cosa que hemos intentado llevar a cabo en este trabajo, con la ayuda de tesis como las de Halliday o Rojo.

2. En segundo lugar, y refiriéndose en particular a los titulares periodísticos, podemos observar que, a pesar de presentar en ocasiones una estructura temática aparentemente peculiar (esto es Tópico, Tema y Rema) no es en absoluto una estructura exclusiva de este registro, pues como hemos demostrado, se da en otros tipos de lenguaje, aunque es mucho más frecuente que el Tópico vaya marcado por partículas y expresiones cuya función primordial es ésa: marcar y delimitar el Tópico de la construcción.

Tendremos, pues, que acudir a ejemplos pertenecientes al registro oral para encontrar escasos ejemplos de la estructura antes mencionada, y que tan «cotidiana» y utilizada es en los titulares periodísticos. Pero mientras enéstos el Tópico no tiene ninguna función, a no ser la de delimitar las fronteras o campo de la conversación, en el lenguaje coloquial, en el discurso diario, este elemento tiene otra función: una función fática, pues viene condicionada por la inseguridad del hablante, que a la vez no quiere interrumpir su intervención. Así, por medio de este elemento la mantiene unida. 